\title{
Video Games as Tools for Education
}

\author{
Arsa Widitiarsa Utoyo \\ School of Design - Visual Communication Design \\ Bina Nusantara University \\ Jakarta, Indonesia \\ arsa_w@binus.ac.id
}

\begin{abstract}
Computer and video games are a channel of evolution and productivity that is most consumed keeping the notice of scholars through a variety of disciplines. In general, computers and video games were ignored by educators. When educators considered the games, they noticed the social consequences of gambling, ignoring the remarkable educational potential of the game. This article looks at the history of educational research games and argues that the perceptive potential of games has been ignored by educators. Current developments in the game, including interactive stories, authoring tools, and digital world collaboration, suggest powerful new opportunities for educational media. Video games are an important part of improving education through its ability to force players to present realistic simulations of real-life situations. The beginning of the proper use of gaming technologies for education and training and there is no need for scientific and engineering methods to create games not only as a more realistic simulation of the physical world but to provide experience Effective learning. This document illustrates building up to date Integration of educational principles and game design into dialogue between them and defining games that can be integrated based on design, entertainment and educational features. The work follows a drawing tray that forms part of the framing definition and after selecting categories of design templates, before focusing on user interaction modes, from a pedagogical point of view, given its relevance to end users
\end{abstract}

Keywords; video games; games; education;

\section{INTRODUCTION}

Over the past 30 years, video games have become an integral part of our culture, and the video game industry has become a multimillion-dollar business. According to the Entertainment Software Association, 59\% of America played video games in 2013. In the same year, consumers spend \$ 2.1 billion of video games. Sony PlayStation system debuted in the US, netting more than $\$ 150$ million in twenty-four hours, more than six times the opening day of Star Wars: The Ghost Threat, which has won \$25 million. Twenty-five million Americans, or a family of four have a Sony PlayStation. Not only video games are a powerful force, not just in the field of entertainment and the economy.

Pokémon Nintendo, who, like Pac-Man and The Mario Brothers before it, has evolved from a game to a cultural phenomenon. Given the pervasive influence of video games on culture, many educators are concerned about the effects these games have on players and how some of the motivational aspects of video games could be wiring to facilitate learning. Some educators fear that video games can encourage violence, aggression, negative images of women, or social isolation [1]. Other educators see video games as powerful digital environments and video game studios to determine how motivational components of the popular instrumental design can be integrated video games [2].

During the Nintendo Age, these studies are few and somewhat dated, given the recent developments in the theory of games and game design. In this article, I argue that video games are so popular and influential media of a combination of many factors. Mostly, however, video games provoke strong emotional reactions to players such as fear, power, aggression, wonder, and joy. Game designers to create these emotions in balance several game components such as character traits, prize games, obstacles, story games, competition with other humans, and opportunities to collaborate with other players. Understanding the dynamics behind these design considerations could be useful for educational technicians that design interactive digital learning expeditions. The video game occurs in rich sociocultural contexts, family reunion, serving teenagers and providing "raw material" for youth culture and friends.

\section{WhY VIDEO GAME}

In 2003, a movement for video games in education and training began. The initiative, known as serious games, has changed the way educators have seen education to meet the needs of network generation. Serious games have impacted the military and firefighters [3], medical [4], and higher business education [5].

Video games are one of the many ways Internet has changed the way a young generation socialize and see entertainment. Today, savage gamblers voluntarily pay monthly online gambling rates as easily as their parents pay electricity bills online-and look forward to new video games how their parents were usually making the ticket queue for the concert. Although video games have been around for over 30 years, it has not been so long since technology has allowed video metamorphosis in descriptive and narrative subjects. The video game industry today is approaching an annual $\$ 15$ billion and approximately $\$ 3.38$ billion revenue. The gambling population falls $10-34$, among many people with 14-19. Games are played not only; Speaking, they are read, fantasy, deceive, alter and become models for everyday life and for the formation of subjectivity and intersubjective. 
There is a politics, economy, history, social structure and function, and the experience of daily life play (Castell \& Jensen, 2003).Believes that the integrated video game teaching method has the potential for non-auto-referential disciplines, especially science; These games were developed by Chris Dede (River City) and Sasha Barab (Quest Atlantis) [5] [6].

This notion caught the attention of those in Washington, DC Beltway. The Federation of American Scientists called the game the next great discovery because they offer a way to seduce students as they spend time learning on their time. Most games developed by commercial games companies mainly focus on first-person shooter games and sport, educational and non-design. The report said commercial games are not an investment that the private industry can take. The federal government must amplify the movement with financial and political support. Examples of games developed now, because this unit can be used for educational purposes are described.

A serious educational game Immune Attack (www.fas.org/indetate), was developed by FAS, Brown University and the University of Southern California. This first-person educational strategy game has been created as an alternative means of teaching complex issues of biology and immunology for students. Here, a teenage prodigy with a single immunodeficiency must teach its immune system how to function properly or die. The human body acts as a field and immune cell face bacterial and viral infection. Each next level of Immune Attack presents a different infection with a new type of immune cells for the player for training, and the player needs to explore and interact with the various objects to train your immune system to fight the invasion of the pathogenic system.

Another example of a Food Force education video game is Food-Force. Created by the United Nations World Food Program in 2005, this serious game involves users in missions to distribute food in a hungry country to help them recover and become self-reliant. The player becomes a scientist who has joined a group of UN experts, including a nutritionist, a logistics officer, a pilot, an audience, and the manager of food purchases. Discover Babylon is the result of collaboration between the Cuneiform Digital Library at the University of California-Los Angeles, the FAS Learning Technologies project, the Entertainment Escape Door and the Walters Art Museum in Baltimore.

This serious multiplayer game is characterized by a historically and scientifically accurate 3D photorealistic simulations and management tools for questions and answers designed to encourage learning. The game is designed to engage children from 8 to 14 years of challenges and mysteries that can only be solved through the development of an understanding of Mesopotamian society, business practices and trade. Atlantis Quest a project funded by the National Science Foundation (NSF) developed by researchers at the University of Indiana, serves as the latest example of virtual environments 3D multiuser created to soak children (age 9-12) into educational tasks. Travelers travel to virtual places (for example, Unity, Ecology, Culture and Healthy World) for teaching activities (Misiones). Students conduct environmental studies investigating other cultures, members of the interview community, and developing action plans to complete their missions [7]. Other examples include Environmental Detectives, developed for Arcade and River City education, developed by Chris De.

These educational games often require the use of logic, memory, problem solving, critical thinking skills, visualization and discovery. In addition, the use of these technologies requires users to reproduce virtual objects using electronic tools and develop an understanding of complex modeling systems. These educational games seem to be effective in improving motivation and increasing students' interest in the subject, however, the extent to which this results in more effective learning is less clear. The lack of empirical data, especially because of the lack of systematic research into the cognitive impact of serious games, forcing us to resort to a previous study by investigating the impact of simulations on interactive computer for testing.

\section{Video Games In EducAtional Settings}

In recent years, video games have begun to mature as a form of entertainment. The most obvious thing is that enormous advances in technology have allowed designers to create rich digital worlds with dramatically improved sounds and graphics. Progress in video game design does a lot more, since real-life gaming experience today is much richer than "Pac-Man". A good game design through these genres immerges users into a rich interactive digital micromodel. Video games can be faced with an F-14 fighter or an entire civilization (Civilization, Age of Empires, Alpha Centauri); They can create a family (The Sims), the social engine of a breed of creatures, explore rich interactive environments (Shenmue), or participate in fantasy / paly role (Final Fantasy VIII). However, very little empirical study of how these games are used, and current research has failed to provide a useful framework for research [8]. This section describes some of the unique features of existing games and simulations, suggesting where they might be useful for educators.

Historically, computers have been used in education primarily as a tool to support exercise and practice for recall done [9]. Exercise exercises and exercises such as AlgaBlaster, Ready Rabbit or Munchers knowledge have been popular because they can easily be integrated into a traditional educational program of "enrichment exercises" during independent study time. Exercise and practice games use the kind of "action" video games to engage students [2]. If a search is made on the effectiveness of these games, but there is no reason to believe that a well-designed video game will produce results that are substantially different from noncomputer games.

Although exercise and practice games can play an important role in student-centered environments, such as problem-based learning, using video games to support 
student learning micromodel exploration. Simulation of the physical system model or social systems through another set of symbols, such as the computer interface. There are two types of simulations and strategy games. High fidelity simulations attempt to model each interaction into a realworld system, while low fidelity simulations simplify a system to highlight the main components of the system. Because they are expensive to produce, usually high fidelity simulations are used when engaging in real activities is prohibitive or too dangerous, and pilot training. Strength in high fidelity simulations lies in its ability to produce where students are expected to participate. Low fidelity simulations are also used when the emphasis is on developing a concentrated understanding that allows students to interact with complex systems by reducing or eliminating extraneous variables. Many low fidelity simulations do not use computer technology; Use role-playing games or simulations to simulate a system, like in the consultants. Computer simulations or educational videogames can be powerful learning tools. They allow learners to:

A. Unalterable manipulate variables. Simulations of natural systems like Sim Earth, students can observe the effects of changing oxygen levels in balloons or raising global temperatures.

B. Allow students to see phenomena of new perspectives. Hidden Agenda in Simulation, students can assume office as a president in a Central American country, learning economics, history, politics, sociology, and culture in the process.

C. Observe system behavior over time. In Simulations like SimCity or Civilization, students can observe the behavior of social systems for years or centuries.

D. Ask questions to a hypothetical system. In historical simulations, such as Antietam, students can simulate hypothetical events.

E. Display a three-dimensional system. In the digital weather station, students use special tools to visualize 3D time systems in three dimensions.

F. Compare simulations of a system. Simulations do not represent reality; They reflect a concept of design reality. For example, SimCity is strongly geared towards public transformation reflecting Will Wright's sympathy with public transport. Educators can take this discrepancy and make students look at a simulation of prejudices or inaccuracies.

By enabling them to interact directly with a model of a complex system, simulations place learners in a unique position to understand a system's dynamics. The educational value of simulations does not necessarily lie in the program itself, but rather in the overall experience of the simulations. Learners need opportunities to debrief and reflect, and the amount of time spent on reflection should equal the amount of time engaging in a game or simulation. Instructors play an important role in this process fostering collaboration, promoting reflection, and coordinating extension activities.

\section{GAME DESIGN PATTERNS}

Video games and simulations (edutainment) are increasingly spreading in the education sector, very little is known about how they work. Much of the research in this area has focused on comparing the game with the magisterium, which is often inadequate because each is a different teaching technique that usually embodies values other than the educational designer and is suitable for different types of learning experiences. Instead of isolating variables which contribute to good game design or comparing games versus other instructional approaches, instructional technologists would benefit from studying programs that use simulations, in the form of case studies, or design experiments.

Practical design tools are needed to effectively apply the educational aspects in the drawings. An important conceptual tool, in this sense, is the definition of pedagogically informed game design patterns. Only on rare occasions, in fact, a game designer and educational / instructional designers share a common vocabulary, which hampers collaborative design efforts. A solution can come from well-known design patterns, collections of reusable solutions to recurring problems. It is important to note that the term design pattern refers to content, in this case, rather than programming. Moving the concept of model design in the field of educational games, has identified several models, which proposed six categories. Here is a summary of how these categories are faced with crucial aspects that educational game designers should consider in designing educational games.

A. Integration patterns describes solutions that harmoniously integrate game elements and learning objectives in pedagogically meaningful ways. How the integration of learning objectives and gameplay can create the foundation of a game and usually arouses constraints that affect the whole design.

B. Cognition patterns describe solutions that trigger reflective and metacognitive processes in players and stimulate players to process relevant content experienced through gameplay. It emphasizes the meaning of cognitive feedback in educational games.

C. Presentation patterns aim to ensure that the player's processing of the content is effective. Learners are challenged to extract relevant information from a game world, select corresponding parts of information and integrate all such elements in a coherent representation.

D. Social interaction and teaching patterns are interwoven into cognition patterns. They describe solutions that facilitate learning or teaching (trigger reflective and metacognitive processes) through social activities and socially constructed game elements.

E. Finally, engagement patterns provide a means of wrapping the whole gaming experience into a meaningful and motivating package. They describe solutions that motivate players to perform better in a game, facilitate learning and increase playing time. 
Educators can also didactic design theory as a framework for understanding the dynamics of didactic application simulations. Regardless, more grounded to help educators understand the dynamics simulation using to promote learning research is needed [10].

A. Interface appeal is key because games, should engaging to play, and because a nice graphic aspect can attract demographics that are traditional averse to instructional activities. In interface design, beside the pure graphical attractiveness, there are also other aspects that should be designed considering also the pedagogical point of view.

B. Method/level of interaction modalities for a game should be decided coherently with the application's educational strategy, which in turn is to be determined by the game's inspiring pedagogical principles. For instance, question and answer environments, like simulations or adventure games, where inquiry or discovery learning strategies are adopted, are fully interactive and, at a further level, additional interaction.

C. Feedback and reward provided by the system because of user actions is a key point for all types of digital educational products

D. Type of evaluation of performance and level of metacognitive support provided, the capacity of the digital tool to provide users with a proper evaluation of their performance is a key aspect to support and enhance the video game effectiveness and impact. his is expected to guarantee that users are fully aware of their successes/failures, so that they are in a better position to improve their performance. Embedding formative and/or summative evaluation elements in the game has different pedagogical implications closely related to the level of performance awareness which, in turn, has clear implications on metacognition and metacognitive aspects of learning behavior.

\section{From THEORY TO PRACTICE}

The virtual world where a game is established can provide valuable education value. Various series of effective videos - they also have a counterpart in successful games such as entertainment like Grand Theft Auto and Oblivion has an organization that tends to support players in building a knowledge of the appropriate structure the subject (S). In a rough way, the model is composed of (1) a space-based world - virtually where knowledge is distributed and induces spatial information processing and provides reference points for support orientation; (2) activities that are spread and contextualized in the contextual contextualized word. Tasks include knowledge units that the player can discover. Based on the theory of learning tasks emphasizes the importance of concrete activities and building knowledge and developing concentrated skills.

A player explores the environment by performing missions involving a sequence of small tasks, each of which has a specific and limited scope of instructions. The pedagogical utility of this approach was discussed in presenting the experience of my Assistant Learning, emphasizing the importance of encouraging students through timely and responsive questions and answers [11]. The complexity of tasks, due to the difficulty of tasks and the environment to be explored, which can gradually grow towards ever more complex goals, activities can be patterns of patterns (for example, various types of mini-games with different content), With the advantage that interaction modes can be reused by the player in various contexts, while maintaining low cognitive load, which is good for theory cognitive load. Additionally, the development of activities can be effectively supported by a kit of authoring tools that allows teachers and students to develop / personalize the content [12].

The availability of a large database of semantic annotated tasks leads to the possibility of dynamic planning activities. Bellotti et al. [13] have a driving experience that explores computational intelligence to plan operations for estimated user performance profile and to keep students in the appropriate area the needs for proximal development and "Implementing a Strategy This system, once again, can provide a level of guidance that should help students maximize their exploration without losing a potentially high space of knowledge. In the proposed approach, a game does not need to A detailed specification of the story There is a high-level challenge (for example, a treasure hunt) that encourages players to compete / collaborate through exploration a virtual word. This simple narrative structure would make the player less cognitive, leaving more space to gain knowledge. Activities can be of a different type, also supporting different styles of learning [14] They stand out in the game, either to improve student skills or to make learning easier, taking advantage of their favorite skills - depending on the master's strategy. In fact, the methodology allows the teacher to specify the requirements for a planning policy at run time to maximize learning objectives. Politics is learned from the United States, which is responsible for planning the final activity. The criterion allows the teacher to define different educational goals, which should curve the difficulty and the overall distribution of learning style tasks [13]. Allows the teacher to specify the requirements for a runtime scheduling policy that maximizes learning objectives. The policy is learnt by the EE, which is the responsible for the final scheduling of the task. The policy allows the teacher to define several educational targets, among which the expected difficulty curve and tasks' overall learning style distribution [12].

\section{CONCLUSIONS AND FUTURE WORK}

Video games are an important opportunity to improve education, even in a lifelong learning perspective, thanks to its ability to force players and provide realistic simulation opportunities. In addition to this, there is the awareness that we are at the beginning of a proper use of education technologies and education and there is a need for scientific methods to build games to provide effective learning experiences. This requires closer cooperation between the 
various actors involved in the overall gaming chain (students, teachers, educators, promoters, businesses, etc.) In this work, the inadequate integration of the principles of didactic design and gameplay are the recipients and methods and mechanisms that allow designers with different backgrounds to speak to each other and define the games that integrate, according to design, entertainment and educational features Are proposed. We believe that the information provided in this document may be useful for researchers and stakeholders to understand the typical game design issues and to draw inspiration about games that are both effective as entertainment tools as educational tools.

The next steps in our research refer to improved / technical models presented (for example, paintings, design patterns, interaction patterns, and serious sandbox game models). At the same time, these techniques or the like can be evaluated and improved by other experts and researchers to reach the long-term goal of defining the appropriate standards and models for effective video game design.

\section{REFERENCES}

[1] Provenzo, E.F. 1992. What do video games teach? Education Digest, 58(4), 56-58.

[2] Bowman, R.F. 1982. A Pac-Man theory of motivation. Tactical implications for classroom instruction. Educational Technology 22(9), 14-17.

[3] Harmon, A. (2003, April 3). More than just a game, but how close to reality? As a war tests its value, video training draws praise and concern in the military. The New York Times. Retrieved April 3, 2003, from http://query.nytimes.com/gst/fullpage.html? res=9B0CE3D81F39F930A35757C0A9659C8B63

[4] Craft, J. (2004). A review of what video games have to teach us about learning and literacy. Cur- rents in Electronic Literacy, 8.
Retrieved 3 , March 3 http://www.cwrl.utexas.edu/currents/ fall04/craft.html

[5] Bos, N. D., Shami, N. S., \& Naab, S. (2006). A globalization simulation to teach corporate social responsibility: Design features and analysis of stu- dent reasoning. Simulation \& Gaming, 37(1), $56-72$

[6] Cosman, P., Cregan, P., Martin, C., \& Cartmill, J. (2002). Virtual reality simulators: Current status in acquisition and assessment of surgical skills. Anz Journal Of Surgery, 72(1), 30-34.

[7] Barab, S., \& Luehmann, A. L. (2003). Building sustainable science curriculum: Acknowledging and accommodating local adaptation. Science Educa- tion, 87, 454-67.

[8] Gredler, M.E. 1996. Educational games and simulations: A technology in search of a research paradigm. In In Jonassen, D.H. (Ed.), Handbook of research for educational communications and technology, p. 521-539. New York: MacMillan.

[9] Jonassen, D.H. 1998. Integrating learning strategies nto courseware to facilitate deeper processing. In David H. Jonassen (Ed.), Instructional Designs for Microcomputer Courseware (pp. 151181). Hillsdale, New Jersey: Erlbaum.

[10] Reigeluth, C.M. \& Squire, K.D. 1998. Emerging work on the new paradigm of instructional theories. Educational Technology,38(4), 41-47.

[11] Frazer, A., Argles, D., \& Wills, G. (2007, July). Is less actually more? The usefulness of educational mini- games. In Advanced Learning Technologies, 2007. ICALT 2007. Seventh IEEE International Conference on (pp. 533-537). IEEE.

[12] Bellotti, F., Berta, R., \& De Gloria, A. (2010). Designing effective serious games: opportunities and challenges for research. International Journal of Emerging Technologies in Learning (iJET), 5(2010), 22- 35.

[13] Bellotti, F., Berta, R., De Gloria, A., \& Primavera, L. (2009). Player Experience evaluation: an approach based on the Personal Construct Theory. In Entertainment Computing-ICEC 2009 (pp. 120-131). Springer Berlin Heidelberg.

[14] Bellotti, F., Berta, R., De Gloria, A., \& Primavera, L. (2009). Adaptive experience engine for serious games. Computational Intelligence and AI in Games, IEEE Transactions On, 1(4), 264280. 